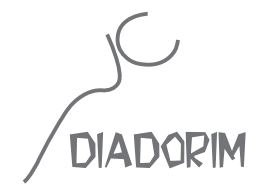

GOMES, Carlos Magno. Marcas da violência contra a mulher na literatura. Revista Diadorim / Revista de Estudos Linguísticos e Literários do Programa de Pós-Graduação em Letras Vernáculas da Universidade Federal do Rio de Janeiro. Volume 13, Julho 2013. [http://www.revistadiadorim.letras.ufrj.br]

\title{
MARCAS DA VIOLÊNCIA CONTRA A MULHER NA LITERATURA
}

\author{
Carlos Magno Gomes ${ }^{1}$
}

\section{RESUMO}

Este artigo traz um estudo sobre as representações da violência contra a mulher na literatura brasileira contemporânea. Analisam-se diferentes formas de femicídio - o homicídio feminino - com destaque para essa violência no conto “A língua do P” (1974), de Clarice Lispector. Metodologicamente, parte-se das abordagens sociológicas que envolvem esse crime, propostas por Heleieth Saffioti e Lia Zanotta Machado. Com uma abordagem politizada da Lei Maria da Penha, investiga-se o crime contra mulheres como parte da violência da sociedade patriarcal.

PALAVRAS-CHAVE: violência doméstica, personagem feminina, corpo disciplinado.

\section{ABSTRACT}

This work presents a study about the representation of violence against women in Brazilian contemporary literature. Different forms of femicide - woman homicide - are analyzed, especially domestic violence, particularly in the short story "A língua do P" (1974), by Clarice Lispector. Methodologically, we take as a starting point the sociological approaches proposed by Heleieth Saffioti and Lia Zanotta Machado. With a political approach to the Law Maria da Penha, the crime against women is investigated as part of the violence inherent in patriarchal society.

KEYWORDS: domestic violence, female character, disciplined body. 
Apesar dos avanços e das conquistas femininas, a sociedade brasileira vive uma epidemia de violência contra a mulher. Mesmo com a sanção da Lei Maria da Penha, em 2006, o Estado ainda não consegue garantir o direito de liberdade de mulheres ameaçadas por seus companheiros. Por isso, o homicídio de mulheres, o femicídio, continua sendo um dos crimes que mais nos assusta na contemporaneidade. Entre violências físicas e simbólicas, ele continua sendo marcado, quase sempre, pelo horror com que o homem elimina sua companheira, após o término de uma relação. Trata-se de um crime passional que nasce na tênue fronteira entre a integridade da mulher e sua sujeição ao companheiro (SAFFIOTI, 1999, p. 84).

Esse crime é parte da violência doméstica, praticada por alguém próximo da mulher. Normalmente, o criminoso é um parceiro com o qual a mulher mantém ou manteve alguma estabilidade afetiva. Lia Zanotta Machado chama a atenção para os dados desta triste estatística: quase 77\% desses assassinatos são cometidos por homens abandonados. Para piorar esse quadro, na grande maioria das vezes, tal crime é antecedido por agressões físicas e sexuais. Portanto, “os femicídios são 'domésticos' e se traduzem no ponto final da escalada desta violência doméstica cotidiana” (MACHADO, 2006, p. 15).

$\mathrm{Na}$ literatura brasileira, há diversos registros de violência contra a mulher associados aos comportamentos próprios de uma sociedade patriarcal tradicional. De diferentes formas, a postura do agressor é representada como parte de uma cultura dominante, por isso incorporada aos padrões sociais disciplinadores. Desde o século XIX, a literatura registra tanto as sutilezas como o horror da violência física e simbólica que sustentam a dominação masculina. Do término do casamento ao assassinato brutal da mulher, a honra do patriarca dá sustentação à barbárie.

Essa violência está representada de forma sofisticada nas atitudes vingativas de Bentinho, narrador de Dom Casmurro, de Machado de Assis. Ele passa a perseguir Capitu, após desconfiar de que foi traído. Tal traição não é comprovada, mesmo assim o narrador se mostra amargo e pessimista. Como punição, ele decide exilar Capitu. Em vez da agressão física, Bentinho opta pelo suplício público da parceira ao mantê-la longe de seu espaço social. Tal exílio faz parte da vergonha social por que a mulher tem que passar publicamente quando paira sobre ela a desonra do marido. Na ficção, Capitu paga pelo possível crime que não cometeu, o adultério, pois nada fica provado. Dessa forma, Dom Casmurro, com sua postura patriarcal, expõe a violência doméstica ao silenciar a mulher acusada de adultério.

No romance regional, o femicídio é parte das estratégias de manutenção da honra masculina, por isso não causa espanto quando acontece. Menino de engenho, de José Lins do Rego, traz a representação desse crime como parte da cultura e como uma opção aceitável para um marido traído. O pai do narrador, Carlos, mata a esposa após descobrir a traição. De forma repentina, esse crime nasce do descontrole masculino e se justifica como tal, pois, historicamente, "[o] femicídio cometido por parceiro acontece, numerosas vezes, sem premeditação" (SAFFIOTI, 1999, p. 83). Na ficção de Rego, o femicí- 
dio não é questionado em nenhum momento da narrativa, pois o homicida enlouquece e se mata, restando o sentimento de pena e compaixão a seu favor. Vale destacar que, mesmo sendo criado pelo avô, no engenho, sem o carinho materno, sem os cuidados necessários, o narrador adulto não questiona a postura do pai. Pelo contrário, a morte trágica da mãe é vista como parte da tradição daquela região.

Diferente dessa postura que narra a opressão e a violência contra a mulher como regras sociais da tradição patriarcal, a literatura de autoria feminina, no século XX, passa a questionar os diferentes tipos de violência física e simbólica contra a mulher quando repudia a dominação masculina. Em $O$ quinze (1930), de Rachel de Queiroz, Perto do coração selvagem (1944), de Clarice Lispector, e Ciranda de pedra (1954), de Lygia Fagundes Telles, as protagonistas fogem de casamentos tradicionais e buscam a liberdade longe de homens dominadores e ciumentos.

A metáfora da liberdade feminina faz parte do projeto estético desses romances. Considerados fundadores de uma genealogia espacial feminina, eles propõem diferentes saídas para suas protagonistas, que repudiam a violência simbólica. O diferencial dessas obras é construído pela capacidade de o narrador desnudar as sutilezas da violência emocional pelas quais as personagens femininas passam. Nesse tipo de ficção, a violência contra a mulher é descrita como uma prática abusiva, seja a física, a sexual ou a emocional. O romance de autoria feminina traz tais abusos como parte das normas familiares. Essa violência não ocorre isoladamente, pois "qualquer que seja a forma assumida pela agressão, a violência emocional está sempre presente" (SAFFIOTI, 1999, p. 84).

Especificamente, a partir dos anos 70, a escritora brasileira passa a explorar os crimes contra a mulher como parte da violência da família patriarcal. Clarice Lispector, Lygia Fagundes Telles, Marina Colasanti, Lya Luft, Nélida Piñon, Patrícia Melo, entre outras, questionam as diferentes formas de violência contra a mulher que vão do assédio moral, passando pelo espancamento, até chegar ao femicídio. Neste artigo, apresentamos uma visão panorâmica de como a violência contra a mulher é construída na literatura brasileira, com destaque para a forma como o femicídio é narrado em "A língua do P", da coletânea A via crucis do corpo (1974), de Clarice Lispector. Teoricamente, exploramos conceitos de violência propostos pelas ciências sociais com destaque para as análises antropológicas de Lia Zanotta Machado e Heleieth Saffioti.

Em estudo sobre a representação da mulher na ficção brasileira, Elódia Xavier destaca a presença da violência simbólica e a falência da família patriarcal como particularidades das narrativas brasileiras de autoria feminina. A pesquisadora identifica diversas formas de representação do corpo feminino, questionando a opressão masculina e pregando o direito de liberdade da mulher.

Além do espaço da casa, Xavier analisa diferentes formas de como o corpo feminino é representado em relação ao patriarcado. Entre os mais encontrados na ficção de autoria feminina, ela des- 
taca: o "disciplinado", que ressalta a norma; o "degenerado", que avulta as regras de violência contra a mulher; e o "liberado", que expressa a liberdade da mulher como mentora de sua vida social e psíquica (2007, p. 22). Com tal análise, essa pesquisadora ressalta o quanto a escritora brasileira apresenta uma ficção preocupada com a crítica ao patriarcado e com a busca da independência da mulher.

Partindo de um estudo histórico, Constância Lima Duarte destaca que a luta da mulher contra a violência física e simbólica sempre esteve na pauta da luta feminista brasileira. Sua pesquisa aponta quatro momentos históricos da luta das mulheres por seu espaço no Brasil. No primeiro, destaca a produção pioneira de Nísia Floresta sobre os direitos das mulheres. No segundo, a partir de 1870, ressalta o surgimento de jornais e revistas voltados para o público feminino. No terceiro, aborda a mobilização da mulher pelo voto, no início do século XX, e pelos direitos iguais para todos. No quarto, a partir da década de 70, enfatiza a luta feminista pela liberdade do corpo da mulher, pelo controle da maternidade e por sua independência financeira (DUARTE, 2007, p. 131).

No contexto dos anos 70, o feminismo ganhou uma face mais politizada e passou a integrar os discursos de artistas em tempo de controle e de censura imposta pela ditadura militar. Assim, além das questões sociais, a feminista dessa época posicionou-se contra todos os tipos de censura (DUARTE, 2007, p. 132). Portanto, a violência contra a mulher é parte dos temas contemporâneos e como tal merece estudos mais aprofundados sobre os recursos usados pela escritora brasileira para questionar essa forma de barbárie.

Além desses trabalhos, diversas pesquisas sobre os estudos de gênero na literatura brasileira vêm mapeando as estratégias de resistência exploradas na literatura de autoria feminina. Por meio de diferentes abordagens, constatam que a escritora brasileira não privilegia o prisma do sujeito universal, pelo contrário, defende o lugar de fala da mulher a partir das subjetividades e particularidades de sua performance social (ZOLIN; GOMES, 2010, p. 09). A ficção ressalta a violência como consequência da falta de habilidade do companheiro em não aceitar a premissa de que a mulher está em transformação e em busca de novos espaços sociais.

Nesse caso, a violência também pode ser vista como um ato de desespero de homens que não aceitam nem o sucesso social, nem o direito à liberdade das mulheres. Dessa forma, destacamos o fato de a flexibilidade da identidade de gênero não ser reconhecida pelo agressor masculino. Daí a importância dos estudos feministas e de gênero para uma avaliação das representações simbólicas dessa violência na ficção brasileira. Se, no campo social, tem-se a tradição cultural da dominação masculina; no campo artístico, tem-se o repúdio de tal cultura. Tal descontinuidade acontece quando a escritora desloca a mulher do espaço da família para um lugar de fronteiras, para atualizar conceitos identitários nos quais a mulher é vista como "algo sempre incompleto e em transformação" (FUNCK, 2011, p. 71). 
Vale lembrar que, a partir do contexto de luta feminista, a ficção tenta ir além da questão moral da violência doméstica e passa a questionar o fato de essa violência estar relacionada à defesa da honra masculina. Nesse sentido, diversas pesquisas apontam que o controle do poder e a defesa da honra estão entre os motivos da violência contra a mulher, pois "em nome do controle, do poder e dos ciúmes, os atos tendem a ser de violência cotidiana e crônica física, psíquica. Podem e desencadeiam em morte" (MACHADO, 2010, p. 57). Fora de controle, o homem elimina sua companheira por motivos torpes. Esse ser vingativo não cabe mais nos espaços contemporâneos de constantes mudanças dos paradigmas familiares.

Diante desse quadro de violência doméstica, o Estado brasileiro fez sua intervenção ao criar a Lei 11.340, de 2006, que tenta "criar mecanismo para coibir a violência doméstica e familiar contra a mulher" (BRASIL, 2006). Essa lei nasce da luta da farmacêutica Maria da Penha Maia, ao tentar processar seu agressor, o ex-marido Marcos Antônio Herredia, que, apesar de atentar contra sua vida duas vezes, deixando-a paraplégica, teve direito de viver em liberdade. Com essa Lei, a impunidade masculina passa a ser vigiada pelo poder público, que impõe novas sanções aos crimes domésticos.

Além de condenar toda forma de violência doméstica, o Estado procura amparar as vítimas, garantindo-lhes segurança, saúde, alimentação e cultura. Tanto o poder público como as instituições que cuidam dos direitos da mulher defendem que a principal forma de integrar a mulher que sofreu violência passa por garantir-lhe direito "ao trabalho, à cidadania, à liberdade, à dignidade, ao respeito e à convivência familiar e comunitária" (BRASIL, 2006). Para isso, a Lei oferece assistência às mulheres, como atendimento médico, "entre outras normas e políticas públicas de proteção, e emergencialmente quando for o caso" (BRASIL, 2006).

Nesse contexto, as pesquisas antropológicas ressaltam que muitas mulheres buscam homens protetores, todavia encontram controladores e agressores (MACHADO, 2006, p. 14). Tais agressões são justificadas pelo criminoso como tentativas corretivas, isto é, formas de ele salvar seu casamento e se manter no controle da situação. Dessa forma, o agressor tenta disciplinar o corpo da mulher. Sem uma autoavaliação, ele não tem o senso crítico de sua postura dominadora. Para ele, agredir a mulher é proteger sua família. A posição que mistura arrogância e falta de instrução faz parte de uma cultura da violência familiar que vem de fenômenos sociais antigos. Por isso, deve ser combatida pelo Estado, pois "o enfrentamento da violência no Brasil não pode se voltar exclusivamente para o combate à criminalidade organizada, mas deve também enfrentar as violências relacionais entre gênero e intragêneros que vêm de uma longa duração" (MACHADO, 2010, p. 69).

Assim, a violência contra a mulher, no Brasil, tem características comuns nas várias classes sociais e regiões do país. A mulher é vítima não só de um agressor, mas de uma prática cultural. Antes 
do crime passional, há diferentes tipos de violências simbólicas e físicas que fazem parte da intimidade do casal. Estão entre elas: xingamentos, empurrões, surras que causam lesões corporais graves. Mesmo com esse cenário de opressão e disciplina, a maioria das mulheres não denuncia os companheiros por medo ou por não ter condições financeiras para se sustentar. A dependência física e afetiva se mistura em muitos casos. Diversos estudos constatam que sempre há uma esperança de o companheiro mudar e a família ser reestruturada.

Esse tema tem diferentes versões no imaginário da literatura contemporânea. Na década de 70, com a divulgação do feminismo entre as intelectuais brasileiras, a violência contra a mulher passa a ser incorporada como tema da literatura de autoria feminina. Apesar de não ser uma abordagem comum a todas as escritoras, tal violência ganha mais visibilidade e passa a ser encarada como parte da cultura dominante. Nessa linha de reflexão, Marina Colasanti questiona a opressão feminina, em "Moça tecelâ" (1978), por meio de uma paródia da relação controladora do patriarca. No conto, o homem nasce do desejo de a mulher ter um marido. Todavia, após realizar seu sonho, a tecelã passa a ser explorada e escravizada por ele, que a priva do direito de expressão e de liberdade. Ela fica presa o dia todo produzindo o que mais interessa ao homem: bens e riquezas. Como saída, a mulher desfaz o marido e o sistema opressor para viver em liberdade. Dentro das relações de gênero, ela elimina simbolicamente um sujeito que até reconhece o excesso de sua violência, mas considera sua atitude necessária para a melhoria do relacionamento (MACHADO, 2006, p. 14).

Ainda nessa década, Lygia Fagundes Telles lança "Venha ver o pôr do sol”, da coletânea Antes do baile verde (1970), que traz o sombrio e misterioso espaço do cemitério como palco de um femicídio. Esse espaço ressalta a tensão que envolve a violência doméstica. O conto é construído por meio de um elaborado jogo de suspense e mistério que envolve os dois protagonistas Raquel e Ricardo. Com o fim do relacionamento proposto por ela, Ricardo se sente injustiçado e a procura para um acerto de contas. O que parecia mais um encontro de ex-namorados, aos poucos, vai se tornando um ritual macabro de assassinato.

Com atitudes bem pensadas e planejadas, ele age tentando convencê-la de suas boas intenções de revê-la. No princípio, ele se mostra feliz com sua presença, mas se transforma quando ela faz referência ao seu atual relacionamento. A imagem de homem ferido pela rejeição vai sendo construída com o desdobrar da narrativa. Sem querer chegar ao fim do cemitério, Raquel tenta desistir daquele passeio, mas Ricardo consegue convencê-la. Ele rejeita a perspectiva da transitoriedade do sujeito feminino como "algo sempre incompleto e em transformação" (FUNCK, 2011, p. 71).

Dentro desse contexto, observamos que o femicídio pode ser interpretado como parte da cultura patriarcal, ou como um aprisionamento simbólico da mulher a essa cultura, uma vez que a per- 
sonagem se encontra presa a um sistema opressor masculino que utiliza métodos disciplinares para reprimi-la e puni-la por suas opções de novos relacionamentos. Nesse caso, a protagonista foi punida por ter optado por uma vida melhor.

As regras que estão por trás dessa representação de dominante e dominado também são, de uma forma ou de outra, repetidas pela Família, Igreja, Escola e Estado, pois sugerem que a submissão feminina é uma construção cultural padronizada. Por isso, destacamos a coerência cultural de "Venha ver o pôr do sol", quando ressalta a mente monstruosa do agressor como parte de uma cultura da manutenção da honra masculina.

No início da década seguinte, Lya Luft lança seu primeiro romance, As parceiras (1980), sobre o questionamento da rotina de violência sexual a que muitas mulheres foram submetidas em famílias patriarcais. Nessa obra, a família da narradora é iniciada por um avô violento que estupra e agride constantemente a matriarca, Catarina. Após sofrer diversas agressões físicas e sexuais, a avó perde o interesse pelo cotidiano da casa. Isolada, ela é tida como louca e passa a viver no sótão. Tal forma de representação desse crime traz à tona a rotinização da violência e o silêncio que se construiu em torno do problema enfrentado por muitas mulheres vítimas de violência doméstica. Grosso modo, a rotinização da violência sexual é reforçada pelo silêncio e como tal "se constitui em verdadeira prisão" (SAFFIOTI, 1999, p. 88).

Além do espaço doméstico, a violência contra a mulher é praticada como parte da violência urbana. Muitos desses crimes envolvem estupro e agressão sexual, quando a mulher é vítima de desconhecidos. Incorporando essa temática a sua ficção, Clarice Lispector, de forma particular, traça um perfil sádico do homicida no conto "A língua do P", da coletânea A via crucis do corpo (1974). Essa narrativa apresenta uma perspectiva estética híbrida de ficção e jornalismo. Com isso, as fronteiras entre texto e contexto social violento ficam mais explícitas.

Essa obra foi encomendada e gira em torno da sexualidade humana. Nesse conto, particularmente, a autora descreve a fantasia sexual de marginais que falam do prazer de agredir e fazer de uma mulher refém durante um assalto. $\mathrm{O}$ conto associa a violência física como parte da identidade masculina violenta do homem. Diante do imprevisível desejo de domínio e exploração do corpo feminino por meio do sexo e da violência, Lispector constrói uma personagem que resolve se vulgarizar para escapar das garras de seus agressores.

Assim, "A língua do P" narra um femicídio cometido por estranhos. A violência física e a banalização do crime são expostas como parte do mesmo problema. Tal crime nasce de um desejo masculino de possuir uma passageira de um trem. Na narrativa ficcional, há tanto a violência verbal quanto a física. A autora descreve como o desejo de violência se confunde com o desejo sexual, mostrando as 
tênues fronteiras desses anseios masculinos. No primeiro momento, há apenas o assédio sexual com palavrões. No segundo, o estupro seguido de assassinato, expondo a suscetibilidade do corpo feminino aos perigos da violência urbana e aos desejos masculinos incontrolados.

Tal violência se inicia com o assédio sexual de Cidinha, a protagonista, e é finalizada com o estupro e o femicídio de outra mulher. Ao trocar a vítima do crime, Clarice Lispector deixa uma pista do quanto esse crime também é fruto de uma cultura machista opressora. A narrativa apresenta duas perspectivas: a externa, referente ao abuso sexual; e a interna, própria de angústia, horror e medo por que passa a personagem. Esses dois movimentos narrativos são importantes para entendermos o quanto a violência traz consequências negativas para as vítimas, como distúrbios emocionais e a sensação de inutilidade da mulher.

Essas observações partem de um narrador onisciente que convida o/a leitor/a a pensar sobre a vulnerabilidade da mulher. "A língua do P" contrasta a violência sexual com a virgindade de Cidinha, uma "professora de inglês" que entra em choque com a descoberta de que será abusada sexualmente. No trajeto entre Minas Gerais e o Rio de Janeiro, ela se depara com dois homens que passam a assediá-la por meio de uma linguagem cifrada, a língua do "p". A relação espaço-temporal da narrativa ressalta o momento de angústia e aflição do assédio sexual: "Havia um mal-estar no vagão. Como se fizesse calor demais. A moça inquieta. Os homens em alerta” (LISPECTOR, 1998, p. 67).

Nesse sentido, a atmosfera absurda do conto nos remete a uma sociedade de regras aviltantes que concernem ao desrespeito aos direitos da mulher. A cultura da violência é fundada por meio de uma construção simbólica nas relações de gêneros, visto que a "construção hegemônica dos valores do masculino se faz em torno do desafio da honra, do controle das mulheres e da disputa entre homens" (MACHADO, 2006, p. 14). Ao ser vista sozinha e bem vestida, a mulher passa a ser desejada por dois homens que planejam o crime por meio da força e do controle da situação.

Como Cidinha entendia a linguagem que eles usavam, entrou em pânico e num estado de imobilidade no primeiro momento. Ao traduzir o diálogo entre os dois algozes, ela se desespera: "queriam dizer que iam currá-la no túnel... O que fazer? Cidinha não sabia e tremia de medo" (LISPECTOR, 1998, p. 68). Além do terror do ato sexual violento, eles ameaçavam matá-la: "Se resistisse podiam matá-la. Era assim então" (LISPECTOR, 1998, p. 68).

Como saída, ela passa a traçar um plano para se livrar daquele destino trágico. Na sua angústia, pensou: "se eu me fingir de prostituta, eles desistem, não gostam de vagabunda" (LISPECTOR, 1998, p. 69). Tal saída só é possível porque, ao se rebaixar como mulher, ela explora uma visão comum às sociedades patriarcais, segundo a qual o corpo da mulher é desvalorizado, pois é visto com desprezo (XAVIER, 2007, p. 132). Por trás dessa dissimulação da protagonista, o conto mostra o quanto é patética tal desvalorização do corpo da mulher. 
Essa troca de papéis femininos também pode ser vista como crítica ao sadismo que culturalmente é construído em torno do estupro e do desejo masculino por mulheres exemplares. Nesse processo, está em jogo a origem do corpo feminino como fantasia sexual. Os criminosos só se satisfazem se abusarem de uma mulher "de família”. Apesar da violência das palavras e da agressão verbal sofrida, Cidinha se salva por se passar por prostituta. Com gestos sensuais e exibindo um decote, ela foi expulsa do trem, após a denúncia do bilheteiro ao maquinista: "vou entregar ela pra polícia na primeira estação" (LISPECTOR, 1998, p. 69).

Além da tentativa de estupro, Cidinha passa por uma via crucis da violência, após o crime. A invisibilidade da agressão está presente nas sucessivas omissões de que vai ser vítima, retratando o quanto é difícil para a mulher vítima de violência sexual ser protegida pelo Estado. No conto, a versão da mulher não é ouvida, ela passa a ser a culpada e punida por ter se comportado de forma desrespeitosa. Nem os funcionários do trem, nem a polícia protegem a vítima de violência sexual.

Depois de presa por três dias, Cidinha pôde enfim seguir sua viagem de cara lavada. Mas toda aquela humilhação deixou marcas. Passou a se sentir deprimida e confusa, pois ainda era virgem. Para piorar seu estado de desânimo e choque, ficou sabendo por uma manchete de jornal que o homicídio, que era para ser contra ela, aconteceu com uma desconhecida. Essa constatação a deixou mais insegura: "Moça currada e assassinada no trem" (LISPECTOR, 1998, p. 70). Nesse caso, conforme pesquisas já revelaram, o abuso sexual foi usado como um meio para o femicídio, resultado final da violência física contra a mulher (MACHADO, 2006, p. 15).

Ao tocar no femicídio como um crime próprio da violência urbana, Clarice Lispector ressalta o quanto as normas que sustentam simbolicamente a dominação masculina perpassam diferentes relações de poder e desrespeito aos direitos da mulher. Do espaço da família ao espaço urbano, a mulher está sujeita a impulsos masculinos sexuais e agressivos. Com isso, a autora registra atitudes criminosas, relacionadas a impulsos sexuais violentos, que devem ser denunciados e punidos.

Ao abordar esse tema, Clarice Lispector retoma, de forma simbólica, alguns aspectos das convenções de gênero, que ainda fazem parte do modo como a dominação masculina perpassa as relações de poder na sociedade, pois "o próprio gênero acaba por se revelar uma camisa de força: o homem deve agredir, porque macho deve dominar a qualquer custo; e mulher deve suportar agressões de toda ordem, porque seu 'destino' assim determina” (SAFFIOTI, 1999, p. 88).

Assim, o conto de Clarice Lispector vai além de descrever uma vítima do crime sexual, pois faz referência à dupla violência que as mulheres sofrem ao terem sido estupradas: a do criminoso e a da polícia que não investiga adequadamente esse tipo de crime, quando responsabiliza a mulher por atentado ao pudor. Assim, a violência contra a mulher vai além do assassinato, pois passa também pela 
invisibilidade que esses casos sofrem nas delegacias, espaço predominantemente masculino, no qual o corpo feminino sofre novo controle e punição de um corpo disciplinado por "esquemas predeterminados, coercitivos e repressores" (XAVIER, 2007, p. 59).

Assim, salientamos que, quando a escritora brasileira passa a se interessar pela violência contra a mulher, a literatura brasileira apresenta um olhar desmistificador desse crime, expondo as particularidades que envolvem o assédio sexual e a violência doméstica. Marina Colasanti, em "A moça tecelâ", faz uma paródia do mito da origem do corpo da mulher como parte do corpo masculino e questiona o cárcere privado. Esse conto pode ser visto como uma metáfora da liberdade da mulher que se livra do homem opressor. A partir de uma atmosfera de suspense e mistério, Lygia Fagundes Telles descreve a violência contra a mulher em "Venha ver o pôr do sol" como parte da cultura patriarcal. Esse conto alinhava o fascismo por trás do femicídio a partir do questionamento da honra masculina e do desespero do homem quando perde sua parceira.

Com uma postura mais crítica, Lya Luft descreve a violência doméstica como um fantasma da família patriarcal, narrando o estupro por que passava a matriarca da família em As parceiras. Por último, vimos que Clarice Lispector é mais irônica e encara o problema ao relacionar violência sexual e femicídio em "A língua do P”. Nessas obras, a violência contra a mulher é antecedida por questões simbólicas. Tais representações fazem parte de uma cultura calcada na premissa de que o assédio moral e sexual é parte das normas sociais infligidas à maioria das mulheres.

Essas narrativas têm um ponto em comum, o questionamento da violência contra a mulher, quando ressaltam uma postura contestatória explícita. Portanto, o estudo da violência contra a mulher na literatura brasileira nos remete a pensar em saídas e possibilidades para o fim desse crime na moderna sociedade. Nessa perspectiva, vale destacar a força da literatura brasileira de autoria feminina em questionar essa violência, ressaltando o deslocamento social da mulher como oposição à ordem vigente (ZOLIN; GOMES, 2011, p. 07). Tais tipos de opressão estão no cerne da questão da violência doméstica e nas práticas do femicídio e devem ser encarados como um desafio para a sociedade.

No campo social, a punição masculina é uma das saídas para a mudança de paradigma de gênero que está por trás dessa violência. Com isso, destaca-se a importância da Lei Maria da Penha, que busca proteger as mulheres do seu agressor e reverter essa cultura da honra. Ela advém do reconhecimento dos novos valores sociais nos quais a proteção dos direitos da mulher é um dever do Estado. Essa Lei prega o respeito, os direitos da mulher e a igualdade de gênero com o repúdio a qualquer forma de violência, seja simbólica ou física. Com esse cuidado, o fim da violência doméstica pode ser explorado como um indicador de prosperidade social e de pleno exercício da liberdade feminina a partir da execução dessa Lei, que "na prática é um lugar propício para o afloramento dos valores de longa duração de uma forma acrítica por muitos operadores de direito" (MACHADO, 2006, p. 18). 
Artigo recebido:20/01/2013

Artigo aceito: 10/05/2013

\section{REFERÊNCIAS}

BRASIL, Lei $n^{\circ}$ 11.340, de 07.08.2006, cria mecanismos para coibir a violência doméstica e familiar contra a mulher. Lex - Coletânea de Legislação e Jurisprudência: Edição Federal.

DUARTE, Constância Lima. "Pequena história do feminismo no Brasil”. In: CARDOSO, Ana Leal; GOMES, Carlos Magno. Do imaginário às representações na literatura. São Cristóvão: Ed UFS, 2007.

FUNCK, Susana. “O que é uma mulher?” In: Cerrados. Brasília: Pós-Graduação em Literatura, 2011, pp. 65-74.

LISPECTOR, Clarice. “A língua do P”. In: . A via crucis do corpo. Rio de Janeiro: Rocco, 1998.

MACHADO, Lia Zanotta. "Violência doméstica contra as mulheres no Brasil: avanços e desafios ao seu combate". In: BRASIL. Secretaria Especial de Políticas para as Mulheres. Cartilha Violência Doméstica - Protegendo as Mulheres da Violência Doméstica. Brasília: Fórum Nacional de Educação em Direitos Humanos. 2006, pp. 14-18.

MACHADO, Lia Zanotta. Feminismo em movimento. São Paulo: Francis, 2010.

SAFFIOTI, Heleieth I. B. “Já se mete a colher em briga de marido e mulher". In: São Paulo em perspectiva. São Paulo: Fundação SEADE, v. 13, n. 4, oct./dec. 1999, pp. 82-91. Disponível em: <http://www. seade.gov.br/produtos/spp/v13n04/v13n04_08.pdf>. Acessado em 20/02/2013.

XAVIER, Elódia. Que corpo é esse? O corpo no imaginário feminino. Florianópolis: Ed. Brasil, 2007.

ZOLIN, Lúcia Osana; GOMES, Carlos Magno (Orgs). Deslocamentos da escritora brasileira. Maringá: Eduem, 2011. 